\title{
MATERIAL, STRUCTURAL AND MODELLING ASPECTS OF ALKALI AGGREGATE REACTION IN CONCRETE
}

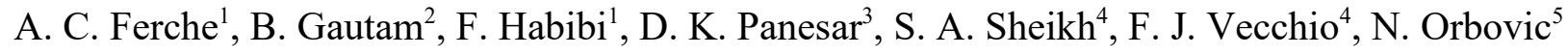 \\ ${ }^{1}$ Doctoral Candidate, Civil Engineering, University of Toronto, Canada \\ ${ }^{2}$ Consulting Engineer, Nepal \\ ${ }^{3}$ Associate Professor, Civil Engineering, University of Toronto, Canada \\ ${ }^{4}$ Professor, Civil Engineering, University of Toronto, Canada \\ ${ }^{5}$ Technical Specialist, Canadian Nuclear Safety Commission, Ottawa, ON, Canada
}

\section{INTRODUCTION}

Alkali aggregate reactions (AAR), particularly alkali-silica reaction (ASR) have been identified in the concrete of nuclear power plants (NPPs) in Canada and elsewhere. This has potentially serious implications on the structural integrity and/or serviceability of aging NPPs (V.E. Saouma, M.A. HaririArdebili, 2014) and there are no currently available assessment criteria or guidelines to assess the consequences. Therefore, an integrated study was conducted at the University of Toronto with funding support through a contract from the Canadian Nuclear Safety Commission. The work is focused on three aspects of this issue namely concrete materials, structural testing, and numerical analysis and assessment. By integrating the material and structural level studies and based on the numerical analysis, this study formulates key performance indicators and the structural assessment criteria, particularly, for assessing nuclear concrete structures affected by ASR. Considering the large scope of the work, this paper mainly provides an overall view of the study and summarizes only the key outcomes of the study. Citations are made to the related theses and research articles which can be referred for an in-depth understanding of the study and its outcomes.

The materials aspects of the reaction have been extensively studied and most of the reaction mechanisms at the material level are understood. However, most of the ASR studies and expansion measurements are based on unrestrained laboratory concrete specimens which limit the ability to predict multiaxial expansions in concrete structures, such as nuclear concrete structures, that are subjected to stresses or restraints in one or more directions. The materials part of this work is, therefore, focused on the characterization of ASR-affected concrete under multiaxial stresses. Some of the test measurements include: axial expansion, damage rating index (DRI) along three planes, nano-mechanical properties by nano-indentation; microstructural analysis; macro-mechanical properties by destructive and nondestructive tests; and evaluation of transport properties.

The structural part of the research program deals with the evaluation of the performance of squat shear walls made with ASR concrete against similar squat shear walls made with normal concrete. Six shear walls were constructed, two with normal concrete and four with concrete containing reactive coarse aggregate. In addition, a large group of the control specimens consisting of 21 cylinders, 3 Modulus of Rupture beams, three expansion prisms, and three Dog-Bone specimens were cast for each type of the concrete. Fifty-two days after casting, the walls and control specimens were stored in an environmental chamber to accelerate the Alkali Silicate Reaction. The temperature in the chamber was maintained at $50^{\circ} \mathrm{C}$ and the relative humidity was $95 \%$. All the walls were tested under reversed lateral cyclic displacement excursions while simultaneously subjected to constant axial load simulating seismic effects.

Two in-house non-linear finite element (FE) analysis programs, developed over the last two decades at the University of Toronto, VecTor2 and VecTor3, were adapted for the analysis of ASR-affected reinforced concrete structures. VecTor2 is applicable to concrete membrane structures, while VecTor3 is 
appropriate for the analysis of three-dimensional structures. The Modified Compression Field Theory (Vecchio and Collins, 1986) and the Disturbed Stress Field Model (Vecchio, 2000) form the theoretical bases of the programs. Reinforced concrete is treated as an orthotropic material based on a smeared rotating crack model within the context of a total-load secant-stiffness macro-modelling approach. The constitutive, compatibility, and equilibrium relationships are formulated in terms of average stresses and average strains (Vecchio, 1989; Vecchio 1990).

\section{MATERIALS LEVEL STUDY}

Two categories of specimens were prepared for this research, namely unrestrained and restrained specimens. The stress state of the cube specimens is shown in Table 1. Destructive and non-destructive tests were carried out at ages ranging from 28 days to 2 years.

Table 1. Average applied compressive stress in concrete cube specimens for the seven stress states

\begin{tabular}{|c|c|c|c|c|c|c|}
\hline \multirow{2}{*}{ Stress state } & Designation & \multicolumn{2}{|c|}{ Average applied stress, MPa } & $\begin{array}{c}\text { Number of } \\
\text { reactive cube } \\
\text { specimens }\end{array}$ & $\begin{array}{c}\text { Number of } \\
\text { control cube } \\
\text { specimens }\end{array}$ \\
\cline { 3 - 6 } & $\mathrm{n}(0,0,0)$ & $f_{x}$ & $f_{y}$ & $f_{z}$ & 4 & 1 \\
\hline No-stress & $\mathrm{u}(3.9,0,0)$ & 3.9 & 0 & 0 & 3 & 1 \\
\hline \multirow{2}{*}{ Uniaxial } & $\mathrm{U}(9.6,0,0)$ & 9.6 & 0 & 0 & 3 & 1 \\
\hline \multirow{2}{*}{ Biaxial } & $\mathrm{b}(3.9,3.9,0)$ & 3.9 & 3.9 & 0 & 3 & 1 \\
\cline { 2 - 6 } & $\mathrm{B}(9.6,3.9,0)$ & 9.6 & 3.9 & 0 & 3 & 1 \\
\hline \multirow{2}{*}{ Triaxial } & $\mathrm{t}(3.9,3.9,3.9)$ & 3.9 & 3.9 & 3.9 & 3 & 1 \\
\cline { 2 - 7 } & $\mathrm{T}(9.6,3.9,3.9)$ & 9.6 & 3.9 & 3.9 & 3 & 1 \\
\hline
\end{tabular}

The mix design was based on the concrete prism test as per ASTM C1293. The water-to-cement ratio was 0.44. High alkali general use (GU) cement was used with a total alkali content of $0.99 \% \mathrm{Na}_{2} \mathrm{O}$ equivalent by mass of cement. The alkali content of the mix was boosted to $1.25 \% \mathrm{Na}_{2} \mathrm{O}$ equivalent of cement by adding $\mathrm{NaOH}$ pellets to water prior to concrete mixing. Two types of concrete were considered, namely reactive and non-reactive (control). The reactive concrete was made with reactive coarse aggregate and non-reactive fine aggregate. The material level characterization of ASR affected concrete was based on Spratt aggregate as the reactive coarse aggregate, which is classified as a highly reactive aggregate (M.D.A Thomas et al, 2012). The control concrete consisted of non-reactive fine and non-reactive coarse aggregates.

The material level concrete was tested in two curing conditions employed to accelerate the ASR damage. (i) $38{ }^{\circ} \mathrm{C}$ temperature and relative humidity $>95 \%$, which is typical of concrete prism test (CPT) and (ii) $50{ }^{\circ} \mathrm{C}$ temperature and $>95 \%$ relative humidity, considered in this study as accelerated concrete prism test (ACPT). The cube specimens were accelerated at $50{ }^{\circ} \mathrm{C}$ and $>95 \%$ relative humidity. Two sets of prisms and cylinders were investigated for the conditioning temperature of $50{ }^{\circ} \mathrm{C}$ and $38{ }^{\circ} \mathrm{C}$.

Prism specimens were measured for axial expansion, examined for DRI, tested for modulus of rupture, resonant frequency, UPV and surface resistivity. Cube specimens were measured for UPV and axial expansion along three directions. DRI was performed along three mutually perpendicular planes. Cores from the cube specimens were tested for static modulus of elasticity and compressive strength. Cylinders were tested for UPV, bulk resistivity, compressive strength and static modulus of elasticity. A detailed information about the various tests conducted in this study can be found in Gautam (B.P. Gautam, 2016). 


\section{RESULTS AND ANALYSIS FROM MATERIAL STUDY}

This section presents few experimental results from the materials level study. Readers are requested to refer to a PhD thesis (B.P. Gautam, 2016) and journal articles (B.P. Gautam, D.K Panesar 2017, B.P. Gautam et al, 2016, B.P. Gautam, D.K Panesar 2017, B.P. Gautam et al, 2017) for the detailed results. As detailed by Gautam and Panesar (B.P. Gautam, D.K Panesar 2017), an increase of $12{ }^{\circ} \mathrm{C}$ temperature from 38 to $50{ }^{\circ} \mathrm{C}$, yields an expansion in ACPT to be 3.22 times faster than in CPT. Except for the rate of expansion, the general trend of expansion and the ultimate expansion were similar for both the ACPT and CPT specimens. These results indicate that despite having different rates, the trend and ultimate expansion are likely to be similar at different temperatures, and hence, ASR in concrete structures can be reasonably represented by experimental results from accelerated test methods.

Expansion is one of the most obvious effects of ASR and has been the fundamental indicator for ASR in concrete specimens. DRI appears as a suitable technique to indicate the performance of ASRaffected concrete. Modulus of rupture reduced by approximately $60 \%$ due to ASR. Splitting tensile strength was also highly sensitive to ASR. This is anticipated because ASR causes cracking, and tensile strength is directly influenced by cracking. Thus, structures that are critical to tensile strength are expected to be affected the worst by ASR. Modulus of elasticity for the non-reactive concrete increased by about $8 \%$ during one year of accelerated curing and it decreased by approximately $25 \%$ for the reactive concrete. Compressive strength increased for both reactive and non-reactive concrete in the accelerated curing regime in this study and was not found sensitive to indicate the performance of concrete affected by ASR. Therefore, compressive strength of cores taken from an ASR-affected concrete structure may not be a suitable performance indicator for the structure unless compressive strength is the critical property.

The ultimate expansions for the various stress states are presented in Figure 1. The figure shows some marked differences in expansions among the different stress states. When the specimens were restrained biaxially in the $\mathrm{X}$ - and Y-directions, the expansion was suppressed in both of the stressed directions. Consequently, increased expansion was observed in the stress-free $(Z)$ direction. The expansion in the Z-direction not only was significantly greater than the free expansion of the no-stress specimen, but also increased with an increased stress level in the X-direction. The volumetric expansion was significantly reduced for the triaxially stressed specimens. These results demonstrate a clear trend of expansion transfer from stressed to stress-free directions. The volumetric expansion due to ASR tries to get conserved as long as there is at least one unrestrained direction.

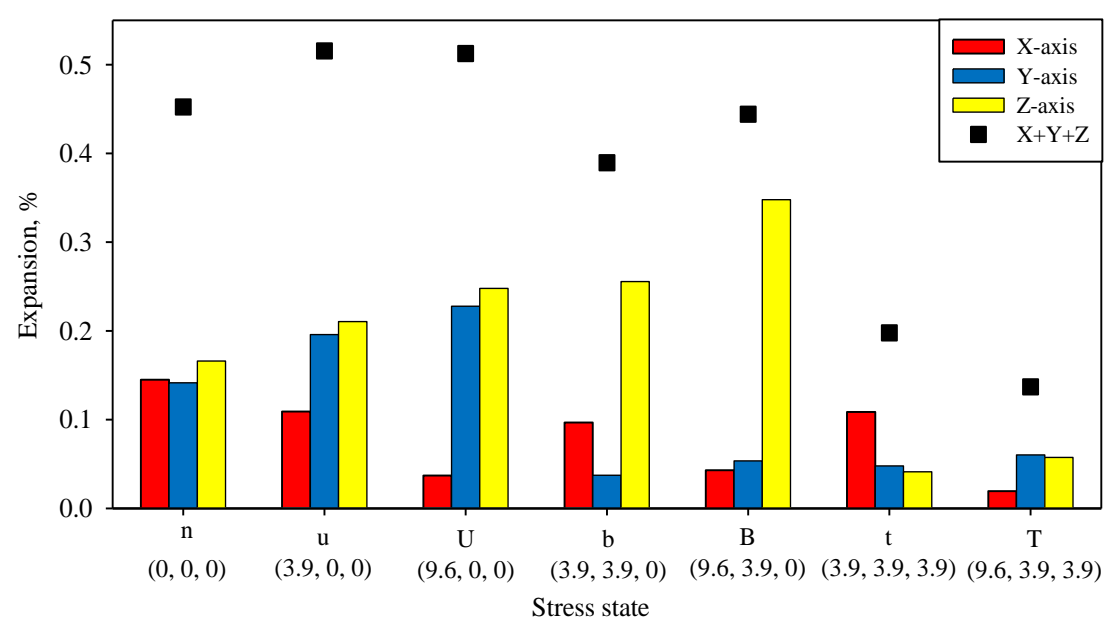

Figure 1. Longitudinal and volumetric expansion $(\mathrm{X}+\mathrm{Y}+\mathrm{Z})$ at 12 months of accelerated curing 
For concrete structures with restraint in one or two directions, expansion can be significantly suppressed in the restrained directions. However, significantly larger expansion can occur in the unrestrained directions. Based on the stress state in the other two perpendicular directions, the expansion in an unrestrained direction can be significantly greater than the unrestrained axial expansion, such as that indicated by a concrete prism test. For planar structures, such as walls, the out-of-plane expansion could be significantly larger than the in-plane expansion. Accordingly, monitoring the expansion in the stressed direction of a concrete element or structure may not be an adequate performance indicator as it can underestimate the extent of ASR damage on the structure.

Detailed results on DRI analysis of cube specimens can be found in Gautam (B.P .Gautam, 2016). DRI was sensitive to the stresses along different directions indicating that DRI in a concrete sample from a concrete structure should be performed along different planes to completely capture the extent of damage. Unlike expansion measurement, DRI can be examined in a concrete sample with no need of a previous reference. The thorough examination capability of the concrete quality, increased sensitivity (compared to expansion) of DRI in restrained concrete and applicability with no need of a reference measurement make DRI a recommended method for indicating the performance of an ASR-affected concrete structure.

Replicates of cube specimens with all stress states were core drilled after unbolting at 3,8 and 12 months of accelerated curing. The cores were tested for the modulus of elasticity and compressive strength. The details are found in Gautam (B.P .Gautam, 2016). A remarkable observation was that, as shown in Figure 2, the mechanical properties were different between the two cores taken from stressed and unstressed directions of a pair of identical biaxially stressed specimens. These results indicated that ASR-affected concrete behaves orthotropically in the presence of different stresses along different directions.

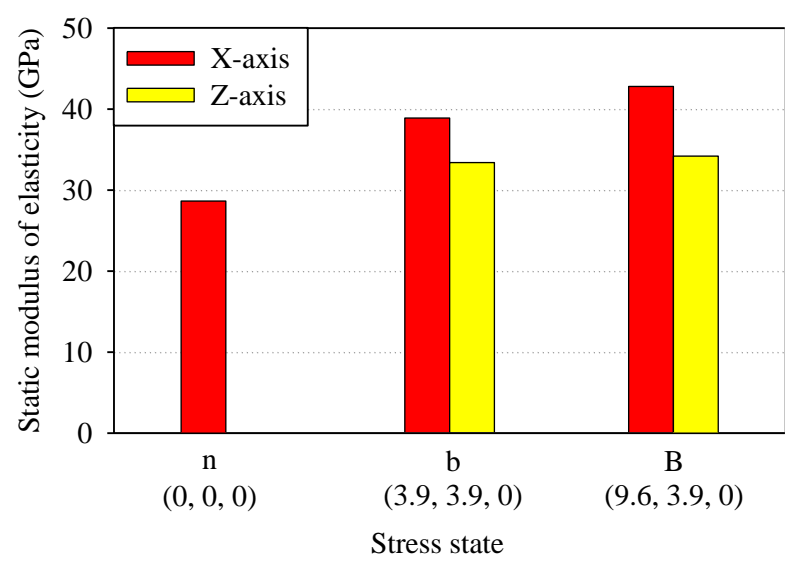

Figure 2. Static modulus of elasticity along the stressed (X-axis) and unstressed (Z-axis) directions in the biaxially stressed specimens at 8 months of accelerated curing

The expansion results for various stress states were analyzed to develop an understanding on the effect of compressive stress on ASR expansion. The model was validated by analyzing the experimental cube specimens by using the finite element software VecTor3. Numerical results were in good agreement with the experimental results, thus validating the proposed model. More details regarding the model are reported in Gautam et al. (B.P .Gautam et al, 2017).

\section{STRUCTURAL LEVEL STUDY}

Shear walls were tested in three phases, low damage, moderate damage, and severe damage phase. Low damage phase refers to a stage that first ASR crack on the specimens can be detected by visual inspection. Moderate damage phase refers to the time when a patterns of ASR cracks are formed within the entire specimen, and finally the severe damage phase refers to a stage that the expansion due to ASR has 
reached its exhaustion level and no more expansion is expected from this point onward. In this paper, results from two ASR shear walls A1 and B2 tested at low damage phase and severe damage phase respectively along with result from a Regular shear wall REG B tested in phase 3 are presented. Based on the results from physical observations and monitoring of the specimens, first phase of structural testing was done around 6 months after conditioning of the specimens in the curing chamber started. Severe damage phase was reached after 31 months of storing the shear specimens in the environmental chamber.

All the shear walls were identical in their geometry and reinforcement details. Figure 3 shows the geometry of shear walls. The beams and the boundary elements in the wall were designed with high reinforcement ratio to ensure that no premature failure occurred in these elements before the failure of the internal wall panel.
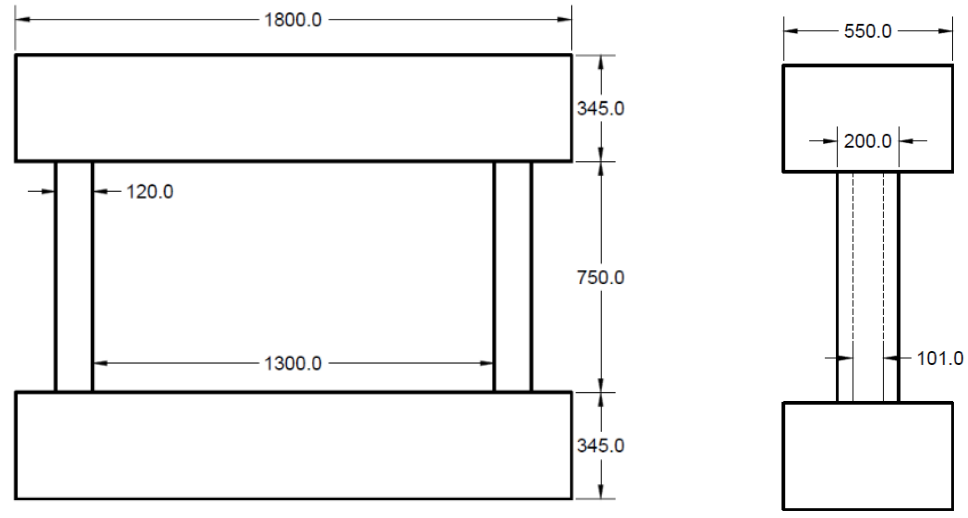

Figure 3. Geometry of Shear Walls

Testing of the shear walls was done using two $1,000 \mathrm{kN}$ actuators and one hydraulic jack capable of applying and maintaining a constant $800 \mathrm{kN}$ axial load. Shear wall was anchored to the strong floor and restrained from both side to prevent any slippage. The Force-Displacement plot was obtained using the summation of the forces from both actuators against displacement of top of the shear panel (bottom of the top beam) with respect to the top of the lower beam. For details of the structural testing and reinforcement details of the shear wall specimens readers are encouraged to refer to the paper "F. Habibi, et al. (2015). "Alkali Aggregate Reaction in Nuclear Concrete Structures: Part 3.

\section{RESULTS AND ANALYSIS FROM STRUCTURAL STUDY}

Table 2 shows a brief summary of the test results. The maximum capacity of the regular shear wall REG B was recorded as $1187 \mathrm{kN}$ and the maximum capacity of the ASR shear wall A1 and B2 was recorded as $1354.5 \mathrm{kN}$ and $1242.7 \mathrm{kN}$, respectively.

Table 2. Summary of Results

\begin{tabular}{|c|c|c|c|c|c|c|}
\hline Wall & $\begin{array}{c}\text { Age } \\
\text { (days) }\end{array}$ & $\begin{array}{c}\text { Compressive } \\
\text { Strength } \\
(\mathrm{MPa})\end{array}$ & $\begin{array}{c}\text { Expansion } \\
\%\end{array}$ & $\begin{array}{c}\text { Peak } \\
\text { Force } \\
(\mathrm{kN})\end{array}$ & $\begin{array}{c}\text { Maximum } \\
\text { Displacement } \\
(\mathrm{mm})\end{array}$ & Mode of Failure \\
\hline ASR A1 & 260 & 63.7 & 0.19 & 1354.5 & 7.1 & Diagonal \\
\hline ASR B2 & 995 & 63.0 & 0.223 & 1242.7 & 2.6 & Diagonal \\
\hline REG B & 975 & 80.1 & 0.0331 & 1187 & 8.1 & $\begin{array}{c}\text { Sliding between } \\
\text { the wall panel and } \\
\text { the bottom beam }\end{array}$ \\
\hline
\end{tabular}


As shown in Table 1, the ultimate shear capacity of these shear walls is approximately similar while a significant drop of maximum displacement and ductility is noticed between ASR A1 tested at 260 days and ASR B2 tested at 995 days. REG B shear wall showed a similar behavior in term of both ultimate lateral displacement and shear strength in comparison with ASR A1 tested in low damage phase. However, comparing the REG B with ASR B2, both tested at the same age, noticeable performance degradation is observed. Lateral force vs. top deflection responses of the three shear walls are shown in Figure 4Error! Reference source not found..

Based on the results from structural testing and control specimens, it is believed that confinement played a critical role in determining the behaviour of ASR A1 shear wall. In all three walls, the top and bottom beams along with the two side boundary elements (columns), induced confinement in the specimens during testing. In the ASR specimens, this confinement was further enhanced due to the restraint developed as a result of expansion of concrete. As the shear wall panel is restrained from all sides, the internal expansion of concrete due to ASR will add significantly to the confinement effect. Since expansion of ASR concrete occurs during curing and conditioning, the reinforcement in the shear wall will undergo a prestressing state thus resulting in a stiffer wall response compared with that of Regular concrete wall. Therefore, at early stages of the damage, these two factors are most likely responsible for the increase in the ultimate strength and increased initial stiffness of the ASR specimen compared with the REG B and ASR B2 walls. The mode of failure is also accordingly affected by the state of confinement in both walls.

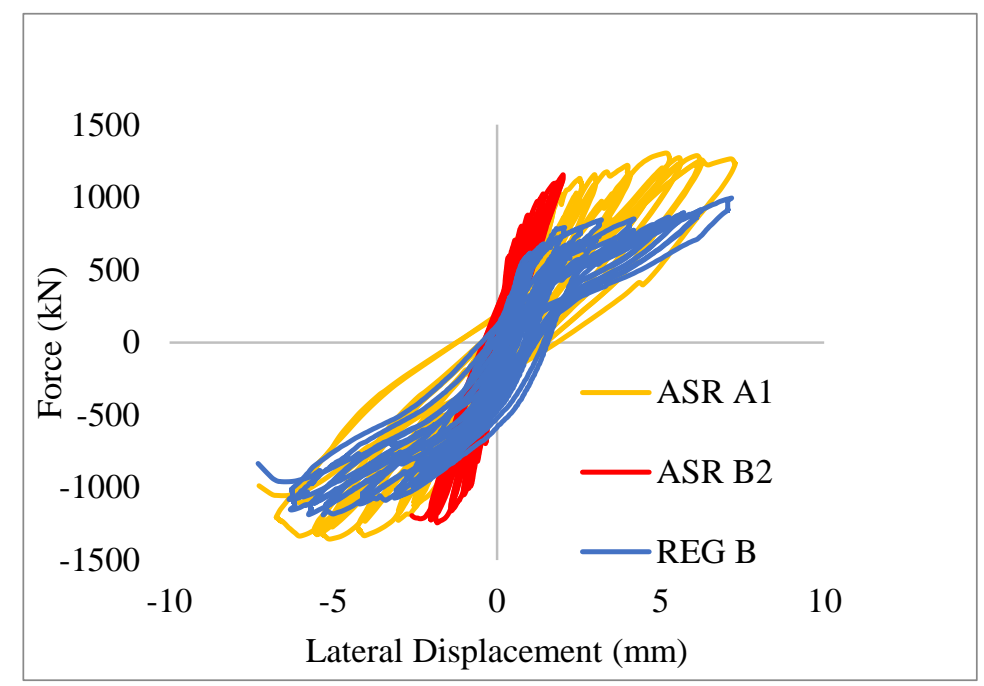

Figure 4. Lateral Load vs. Deflection

In the Regular concrete specimen, the first cracks with widths less than about $0.4 \mathrm{~mm}$ appeared on the shear panel at displacement of about $1.2 \mathrm{~mm}$. Cracks on the columns were initiated later in the test, at a displacement of about $3.5 \mathrm{~mm}$. At $5 \mathrm{~mm}$ displacement, a huge crack was observed in the columns and at $6 \mathrm{~mm}$ displacement, spalling of concrete in column areas was observed. Within this cycle significant spalling of concrete on shear wall panel was noticed accompanied by a diagonal crack which became wider as displacement was increased. The wall carried the maximum load at about $7 \mathrm{~mm}$ deflection beyond which it showed a softening response while still maintaining the $800 \mathrm{kN}$ applied axial load and lost its capacity at a displacement of about $8.1 \mathrm{~mm}$. Final collapse of the specimen was due to sliding of the wall where it meets the bottom beam. Figure 5 shows the Regular shear wall at failure.

Both ASR shear wall specimens cracked initially at an early stage of the experiment, a displacement of about $0.8 \mathrm{~mm}$. Crack widths in this stage varied from $0.1 \mathrm{~mm}$ to $0.6 \mathrm{~mm}$. More cracks then opened up as displacement was increased. In ASR A1, at about $3 \mathrm{~mm}$ displacement, a notable diagonal crack was formed. No spalling of concrete was noticed on the shear wall. However, spalling of the concrete in the column area was observed at $6 \mathrm{~mm}$ displacement. At this stage the diagonal crack in the wall opened 
significantly and eventually the specimen failed to maintain the axial load when the lateral displacement was $7.1 \mathrm{~mm}$. The specimen did not display any significant descending branch of the response. On the other hand, ASR B2 specimen showed noticeably more shear cracks at low displacement. These cracks widened as cycles progressed and eventually the wall failed at ultimate lateral displacement of $2.6 \mathrm{~mm}$ in a brittle manner. See Figure 5 for the ASR shear walls at failure. The final collapse was due to shear failure in the wall panel.
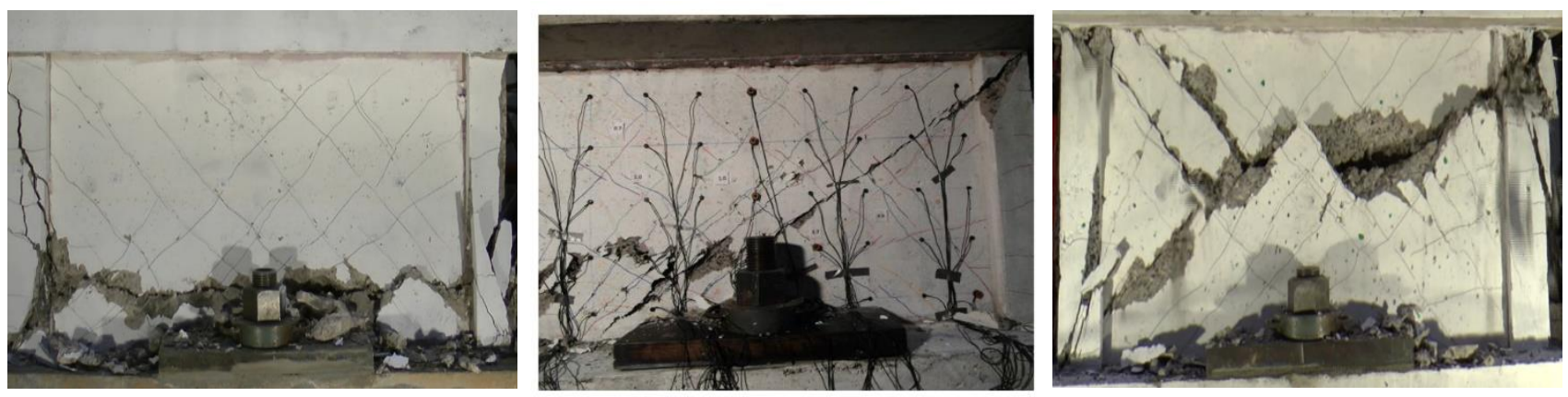

Figure 5. REG B (Left), ASR A1 (Middle) and ASR B2 (Right) at failure

\section{MODELING AND ANALYSIS}

Two in-house non-linear finite element (FE) analysis programs, developed over the last two decades at the University of Toronto, VecTor2 and VecTor3, were adapted for the analysis of ASR-affected reinforced concrete structures. VecTor2 is applicable to concrete membrane structures, while VecTor3 is appropriate for the analysis of three-dimensional structures. The Modified Compression Field Theory (Vecchio and Collins, 1986) and the Disturbed Stress Field Model (Vecchio, 2000) form the theoretical bases of the programs. Reinforced concrete is treated as an orthotropic material based on a smeared rotating crack model within the context of a total-load secant-stiffness macro-modeling approach. The constitutive, compatibility, and equilibrium relationships are formulated in terms of average stresses and average strains (Vecchio, 1989; Vecchio 1990).

The effect of ASR is simulated through two different mechanisms: the induced expansion, and the deterioration of mechanical properties. ASR expansion is treated as an elastic, non-recoverable offset strain, evaluated iteratively in the first load stage of the analysis. The procedure employed was previously developed for elastic and plastic offset strains (Vecchio, 1992). Average long-term loading conditions are considered when performing the ASR analysis. Six models were implemented for the evaluation of ASRinduced expansion: uniform in all directions, Charlwood, Curtis (personal communication, August 19, 2014), Saouma and Perotti (2006), Sellier et al. (2009), and Gautam et al. (2017).

The magnitude of longitudinal expansion developed under stress-free conditions is a required parameter for the ASR analysis. It may be directly input by the user, or it may be evaluated using the Saouma and Perotti or Sellier models, which include a kinetics component. As such, provided that experimental data characterizing the reaction is available from laboratory tests, the free expansion may be determined. Two options are available for considering the changes in mechanical properties. One alternative consists of using the values of the material properties obtained from tests on cores sampled from the structure. The other option evaluates the compressive and tensile strengths, and the modulus of elasticity, as a function of the free expansion based on the ISE (1992) prescriptions. With the latter, lower bounds to the mechanical properties have been defined using values from tests performed on cubes, prisms and cylinders, and on cores extracted from structures. Both options disregard the directional nature of the degradation in mechanical properties caused by the stress level. Both approaches were implemented in the analysis programs. 
Finite element analyses were performed to verify the ASR constitutive models implemented, and the analytical procedure. The verification studies simulated the behaviour of uniaxially loaded cylinders, middle-notched prisms tested under three-point loading, shear and flexural-critical reinforced and prestressed concrete beams, and shear walls.

The flexural-critical specimens investigated did not exhibit a significant reduction in either capacity or ductility due to ASR. Some shear-critical specimens, such as shear walls and reinforced concrete beams provided with transverse reinforcement, showed an increase in strength caused by ASR; an opposite effect was observed in beams with no stirrups.

At the material level, with the exception of the model which evaluates ASR-induced expansion uniformly in all directions, the models yielded similar results. As well, no significant difference in results was observed between the expansion models at the structural level.

The developed procedure showed reasonable accuracy in modeling the response of ASR-affected structures. For the 20 ASR-affected specimens analysed, it gave strengths with a mean calculated-toexperimental ratio of 0.93 and a $\mathrm{COV}$ of $8.0 \%$. The mean experimental-to-calculated ratio for the nonreactive control specimens was 0.97 and a COV of $11.8 \%$. Details on the verification studies and the analytical procedure itself may be found in Ferche et al. (2017), Jurcut et al. (2015), and Jurcut (2015).

Finite element analyses were conducted to investigate the behaviour of the shear walls tested at the University of Toronto. A total of 2260 plane stress rectangular elements were used for modeling the shear wall specimens. The thicknesses of the elements were similar to those of the specimen's sections: the elements in the flanges had a thickness of $200 \mathrm{~mm}$, the elements in the web had a thickness of $100 \mathrm{~mm}$, while the elements in the top and bottom beams were $550 \mathrm{~mm}$ thick. All reinforcement was included in the concrete elements as smeared reinforcement. The support condition was chosen such that it would be representative of the test set-up arrangement and not restrain the ASR expansion. Roller supports in the horizontal direction were defined at the bottom surface of the base. At the mid-depth of the bottom beam a roller support was defined with the degree of freedom restrained in the horizontal direction.

The comparison between the analytical and experimental obtained behaviour is shown in Figure 6 for the REG 1 specimen and ASR A1 specimen. No significant strength degradation was observed analytically due to reverse cyclic loading. The monotonic pushover was similar to the enveloped of the cyclic loading analysis. As such, to increase clarity in presenting the results, the monotonic behaviour is compared with the experimental load-deflection plot. The analyses highlight the influence on the computed behaviour of the post-peak compression model used. Two FE results are presented: one with the Park-Kent compression post-peak model for concrete, the default option; and the second one considering the Hoshikuma model.

The results show good correlation in terms of load capacity for both non-reactive and ASR-affected specimens. The predicted maximum displacement is highly sensitive to the post-peak model chosen for concrete in compression, partly due to the high axial load and due to the geometrical configuration of the walls. The remaining shear wall specimens tested are currently being investigated, and the results will be presented in a future paper. 

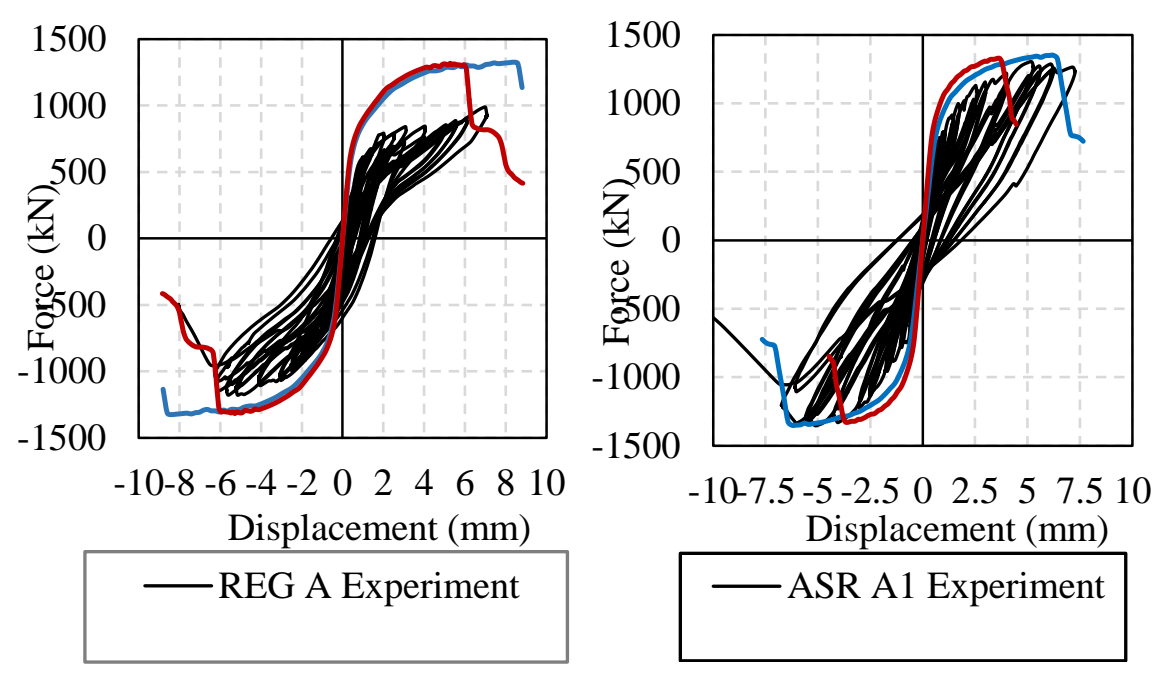

Figure 6. Analytical versus experimental load-displacement behaviour of REG A wall (Left) and ASR A1 (Right)

\section{CONCLUDING REMARKS}

Key outcomes from this research on the materials aspects include: ASR expansion was suppressed due to stress and transferred to free or low stress directions; a constant volumetric expansion was observed for no-stress, uniaxial and biaxial; stress reduces the degradation of mechanical properties. Orientation of cracks was affected by stress such that the opening of cracks was in the direction of free or low stress. Moreover, ASR product underwent physical and chemical transformation with age and the product in the mortar matrix was gradually associated with lime. These transformations were beneficial to partially recover the mechanical properties that had been degraded by ASR.

Based on the results of the structural testing, it can be concluded that ASR did not affect the peak shear strength of the low aspect ratio shear walls. Confinement and pre-stressing of internal reinforcement due to ASR expansion resulted in higher initial stiffness and ultimate capacity of the ASR shear walls. However, ductility and ultimate lateral displacement of low aspect shear walls were considerably reduced as ASR expansion progressed.

Analytical studies have shown that the Disturbed Stress Field Model provides a viable platform for implementing ASR constitutive models into a nonlinear finite element analysis algorithm. Improved accuracy in computational methods could potentially be obtained provided that the following aspects are addressed in further studies: the non-uniformity of the concrete mechanical properties in the principal directions, bond degradation due to ASR, influence of ASR on Poisson's effect, and influence of the aggregate type on the mechanical properties.

\section{REFERENCES}

V.E. Saouma, M.A. Hariri-Ardebili, A proposed aging management program for alkali silica reactions in a nuclear power plant, Nucl. Eng. Des. 277 (2014) 248-264.

ASTM C1293, Standard test method for determination of length change of concrete due to alkali-silica reaction, ASTM International, West Conshohocken, PA, 2015.

M.D.A. Thomas, K.J. Folliard, B. Fournier, G. Ahlstrom, A prescriptive specification for the selection of measures for preventing alkali-silica reaction, in: 14th Int. Conf. Alkali Aggreg. React., Texas, 2012.

B.P. Gautam, Multiaxially loaded concrete undergoing alkali-silica reaction (ASR) ( $\mathrm{PhD}$ thesis), University of Toronto, 2016.

B.P. Gautam, D.K. Panesar, The effect of elevated conditioning temperature on the ASR expansion, 
cracking and properties of reactive Spratt aggregate concrete, Constr. Build. Mater. 140 (2017) 310-320. doi:10.1016/j.conbuildmat.2017.02.104.

B.P. Gautam, D.K. Panesar, S.A. Sheikh, F.J. Vecchio, Effect of coarse aggregate grading on the ASR expansion and damage of concrete, Cem. Concr. Res. 95 (2017) 75-83. doi:10.1016/j.cemconres.2017.02.022.

B.P. Gautam, D.K. Panesar, A new method of applying long-term multiaxial stresses in concrete specimens undergoing ASR, and their triaxial expansions, Mater. Struct. 49 (2016) 3495-3508. doi:10.1617/s11527-015-0734-z.

B.P. Gautam, D.K. Panesar, S.A. Sheikh, F.J. Vecchio, Multiaxial Expansion-Stress Relationship for Alkali Silica Reaction-Affected Concrete, ACI Mater. J. 114 (2017) 171-184.

V. Gocevski, Pathologies/degradation mechanisms experienced by Hydro-Quebec during the evaluation of Gentilly-2 NPP, Hydro-Quebec, Montreal, Canada, 2015.

D.K. Panesar, B.P. Gautam, The mechanisms behind the partial recovery in the degraded mechanical properties of ASR-affected concrete, in: Fib Symp., Cape Town, South Africa, 2016: p. 10.

F. Habibi, S.A. Sheikh, D.P. Panesar, F.J. Vecchio, (2015) and Obrovic, N., (2015). "Alkali Aggregate Reaction in Nuclear Concrete Structures: Part 3: Structural Shear Wall Elements", Structural Mechanics in Reactor Technology (SMiRT) Conference, Manchester, U. K., August 10-14, 2015.

Charlwood R. G., Solymar S. V., and Curtis D. D. (1992). "A Review of Alkali Aggregate Reactions in Hydroelectric Plants and Dams," Proceedings of the International Conference of Alkali-Aggregate Reactions in Hydroelectric Plants and Dams, Fredericton, Canada, 1992, pp. 129-135.

Ferche, A. C. ,Panesar, D. K. ,Sheikh, S.A. , and Vecchio, F. J. (2017) “Towards Macro-Modeling of ASRAffected Structures", Accepted ACI Structural Journal.

Gautam, B. P., Panesar, D. K., Sheikh, S. A., and Vecchio, F. J. (2017). "Multiaxial Expansion-Stress Relationship for Alkali Silica Reaction-Affected Concrete." ACI Materials Journal, 114(1), 171184.

Institution of Structural Engineers (ISE). (1992). "Structural Effects of Alkali-Silica Reaction", SETO, London.

Jurcut, A. C. (2015). "Modelling of Alkali-Aggregate Reaction Effects in Reinforced Concrete Structures", MASc. Thesis, University of Toronto, $136 \mathrm{pp}$.

Jurcut, A. C., Vecchio, F. J., Sheikh, S. A., Panesar, D. K., and Obrovic, N., (2015). "Alkali Aggregate Reaction in Nuclear Concrete Structures: Part 4: Modelling and Analysis", Structural Mechanics in Reactor Technology (SMiRT) Conference, Manchester, U. K., August 10-14, 2015.

Saouma, V., and Perotti, L. (2006). "Constitutive model for alkali-aggregate reactions", ACI materials journal, 103(3), 194-202.

Sellier, A., Bourdarot, E., Multon, S., Cyr, M., and Grimal, E. (2009), "Combination of structural monitoring and laboratory tests for assessment of alkali-aggregate reaction swelling: application to gate structure dam", ACI materials journal, 106(3), 281-290.

Vecchio, F.J. (2000). "Disturbed Stress Field Model for Reinforced Concrete: Formulation", Journal of Structural Engineering, 126(8), 1070-1077.

Vecchio, F.J., (1990). "Reinforced Concrete Membrane Element Formulations", Journal of Structural Engineering, 116(3), 730-750.

Vecchio, F.J., (1992). "Finite Element Modelling of Concrete Expansion and Confinement", ASCE Journal of Structural Engineering, 118(9), 46-56.

Vecchio, F.J., and Collins, M.P. (1986). "The Modified Compression Field Theory for Reinforced Concrete Elements Subjected to Shear”, ACI Journal, 83(2), 219-231.

Wong, P.S., Vecchio, F.J., Trommels, H. (2013). "VecTor2 and FormWorks User's Manual”, 347 pp. 